\title{
La minería cubana en las últimas décadas del siglo XIX
}

\author{
Eduardo L. Moyano Bazzani \\ Escuela Taller del Archivo Histórico Nacional. Madrid \\ Serena Fernández Alonso \\ Centro de Estudios Históricos, CSIC. Madrid
}

\begin{abstract}
El trabajo presentado aborda el estudio de la industria minera en Cuba durante las décadas previas a la independencia en 1898. Con documentación inédita del Archivo Histórico Nacional de Madrid, y como continuación de un trabajo anterior sobre la primera mitad del siglo, los autores analizan el estado de los yacimientos y principales minerales en explotación, su producción y destino de la misma, las compañías mineras implicadas en la extracción y el papel del gobierno metropolitano en el fomento de dicha industria. Se señalan, asimismo, los problemas fundamentales del ramo desde el punto de vista legal, financiero, técnico, así como los acontecimientos históricos que afectaron directamente a su desarrollo.
\end{abstract}

\section{Introducción}

El estudio de la actividad extractiva en la isla de Cuba sigue siendo un campo infravalorado en su interés debido a la visión que de la misma dio la historiografía tradicional. Autores clásicos como Calvache, ${ }^{1}$ entre otros, no dudaron en afirmar que no debió ser importante, puesto que el ilustre barón de Humboldt no hizo mención alguna de ella en su Ensayo Político sobre la isla de Cuba (1827); y en su correspondencia privada con el capitán general de la isla afirmó: "en un país cuya verdadera riqueza consiste en la agricultura... el trabajo en las minas sólo convidaría a la holgazanería en menoscabo de aquélla".2

No obstante esta visión ya convertida en tópico, trabajos recientes que han ahondado, como el presente, en los nutridos fondos de la Sección de Ultramar del Archivo Histórico Nacional de Madrid, ponen de manifiesto que la Corona española, aunque sin duda dio prioridad a otras áreas más productivas de aquel territorio, dedicó gran parte de sus quehaceres a

1 Calvache, Antonio: Historia y desarrollo de la minería en Cuba. La Habana, 1944.

2 Soto González, Luis D.: Apuntes sobre la historia de la minería cubana. Santiago de Cuba, 1981, pág. 32. 
potenciar la explotación minera en Cuba. ${ }^{3}$ Nuestro último trabajo ${ }^{4}$ se centró en demostrar cómo, lejos de ser la actividad minera un ramo marginal de la economía cubana y marginado como se creía del interés del gobierno peninsular, constituyó, por el contrario, uno de los sectores emergentes en la primera mitad del siglo XIX, en gran medida gracias a las iniciativas del gobierno peninsular, que no escatimó esfuerzo alguno (exenciones impositivas, legislación específica, contratación y envío de expertos, etc.) en aras de su fomento y prosperidad.

Con estas páginas se pretende añadir nuevos datos a la visión dada anteriormente sobre las iniciativas renovadoras del gobierno metropolitano en la primera mitad del XIX en el fomento de la minería cuprífera, ampliando el campo de estudio a la actividad extractiva en su conjunto, e incluyendo minerales poco conocidos, en las décadas finales de la dominación colonial. Va en ellas el deseo de contribuir modestamente al conocimiento de lo que ya en la Cátedra de Mineralogía y Geología de la Universidad de La Habana se definió en 1826 como "el oscuro y poco trillado estudio de la minerología". 5

\section{El panorama minero en el período 1868-1898}

Parece un hecho comprobado y generalmente admitido que, al iniciarse la segunda mitad del siglo XIX, la industria extractiva de la isla de Cuba ve roto el ritmo de crecimiento productivo ${ }^{6}$ al que habían contribuido en gran medida factores como la liberación por la Corona de cargas fiscales y de excesivas regulaciones (iniciando desde 1830 una política más transigente hacia los intereses de los empresarios), así como las notables inversiones extranjeras (capital británico y norteamericano) que favorecieron una importante modernización de la tecnología empleada.

3 González Loscertales, Vicente y Roldán de Montaud, Inés: "La minería del cobre en Cuba. Su organización, problemas administrativos y repercusiones sociales (1828-1849)". Revista de Indias. LX, n. ${ }^{\circ}$ 159-162. Madrid, 1980, págs. 255-299.

4 Fernández Alonso, Serena y Moyano Bazzani, Eduardo L.: "Problemas de reforma y conflicto de intereses en la minería cubana de la primera mitad del siglo XIX”. Ponencia presentada a la V Reunión de Historiadores de la Minería Latinoamericana, celebrada en San Luis Potosí (México), en julio de 1997. Trabajo actualmente en prensa.

5 Archivo Histórico Nacional de Madrid (en adelante, AHNM), Ultramar, Fomento, 6. Memoria presentada a la Comisión Regia por las Secciones de Hacienda y Secretaría de Gobernación sobre el ramo de minería en la isla de Cuba. La Habana, 19 de septiembre de 1839. 
Los acontecimientos políticos, en concreto el inicio por Carlos Manuel de Céspedes de la guerra de liberación colonial en 1868, son el detonante de una nueva situación de crisis, pues determinan la paralización de las labores extractivas con la incorporación masiva de operarios a las filas de la revolución.

Junto a ello, los daños causados por las operaciones bélicas vienen a ahondar la ya antigua problemática de las minas cubanas, cuya explotación fue en épocas anteriores anárquica y especulativa, en muchos casos, y dificultosa casi siempre por inundaciones y hundimiento de galerías, con la consiguiente pérdida de las vetas. Es sabido que los empresarios particulares se veían, por todo ello, imposibilitados en su deseo de llevar adelante el laboreo de las minas, debiendo abandonarlas después de denunciarlas, lo que favoreció la proliferación de grandes compañías extranjeras, que acapararon los beneficios de la minería, siendo las únicas con capacidad financiera para asumir los riesgos de la explotación.

Ese efecto negativo de la Guerra de los Diez Años en la economía colonial y, muy directamente, en la minería, se hace aún más evidente si se tiene en cuenta que el escenario clave de las operaciones militares fue, precisamente, la zona minera por excelencia, es decir, el centro y oriente de la isla, fundamentalmente Puerto Príncipe (actual Camagüey) y la jurisdicción de Santiago de Cuba, donde se ubicaban los principales yacimientos y cuya bahía era el puerto de salida de los minerales. Sólo un mes después de haberse producido el "Grito de Yara", se había bloqueado Puerto Príncipe, cortado el ferrocarril de Nuevitas, cercado Santiago de Cuba y destruido el Ferrocarril del Cobre, además de producir innumerables daños y quemas en pequeños poblados.?

Las grandes compañías explotadoras del mineral de cobre, la Consolidada y San José de Santiago de Cuba, se hundieron con la contienda: "destruido su ferrocarril al puerto, incendiadas sus casas, oxidadas y mutiladas sus numerosas y magníficas máquinas de vapor, de extracción y desagüe, y las de preparación mecánica de las menas..." ${ }^{8}$ La destrucción de pueblos y caseríos, la devastación de las haciendas, el arrasamiento de

6 Hacia 1851 Cuba mantenía su posición de principal abastecedor de la industria inglesa, exportando unas 10.000 toneladas de cobre al año, lo que representaba un 12\% de la producción mundial. Citado por Le Riverend, Julio: Historia Económica de Cuba. La Habana, 1974, pág. 369.

7 Moyano Bazzani, Eduardo L.: La nueva frontera del azúcar: El ferrocarril y la economía cubana del siglo XIX. Madrid, 1991, pág. 366.

8 AHNM, Ultramar, Cuba, Fomento, 227, 3. Memoria minera de la isla de Cuba que comprende desde $1 .^{\circ}$ de julio de 1880 a 31 de diciembre de 1881 , fol. 8 . 
ingenios y campos y la dispersión de las poblaciones, fueron efectos inherentes a las acciones militares. Junto a ello, la destrucción de zonas de cultivo, con la consiguiente alza de precios, especulación y huida masiva de población, provocaron una crisis general frente a la que las medidas rehabilitadoras del gobierno poco pudieron lograr. ${ }^{9}$

La Guerra de los Diez Años significó, pues, una conmoción sin precedentes en la economía isleña. En el ámbito concreto de la minería, tras la suspensión total de las labores extractivas durante la contienda, se inicia un período de resurgimiento de la industria minera de Cuba después de 1878. En ese proceso, el fenómeno ya detectado en la primera mitad del XIX del intervencionismo financiero, primero británico y posteriormente estadounidense, se acentúa poderosamente.

Le Riverend juzga determinante en el mismo el desarrollo de la industria metalúrgica pesada en Estados Unidos, precisamente coincidiendo con el período de inactividad productiva en Cuba. La fuerte demanda de materias primas y recursos mineros para alimentar dicha industria, despertarían nuevamente los intereses industriales, orientándose hacia las reservas de Cuba, sobre las que los geólogos norteamericanos ya habían realizado estudios. ${ }^{10}$ Se manifiesta, una vez más, la situación de dependencia económica ejercida por las potencias anglosajonas, tan característica del siglo XIX americano: el llamado "imperialismo contractual", "la fabulosa expansión de los Estados Unidos de América y su constante presión sobre las últimas colonias españolas en el Caribe, según el concepto del mundo como mercado, donde todo tiene un precio y se puede comprar todo, desde un país a una conciencia". ${ }^{11}$

Lo cierto es que la entrada de capital extranjero constituyó el medio más rápido y seguro para insuflar a la maltrecha economía cubana recursos financieros para su reconstrucción. El capital foráneo proveniente de Estados Unidos permitiría, a través de poderosas compañías, poner en explotación a gran escala los recursos minerales cubanos, que sostendrían en gran medida la naciente industria de aquel país. Y aunque el cobre había sido el eje fundamental de la industria extractiva de la isla, otros metales como el hierro, y minerales como el manganeso, el guano o el asfalto, habrán de considerarse en el período postbélico.

9 Le Riverend: Historia económica..., pág. 454.

10 Ibídem, pág. 502.

11 Céspedes del Castillo, Guillermo: América Hispánica. (1492-1898). Barcelona, 1983, pág. 475 . 
La presencia de compañías norteamericanas en la explotación de los mismos, se deja sentir con renovada fuerza en contraste con la primera mitad del siglo XIX, en que las inversiones eran fundamentalmente británicas y de tipo indirecto, a través de créditos y empréstitos aplicados por apoderados en empresas aparentemente cubanas o casas de comercio norteamericanas establecidas en Cuba. "Pero es que entre 1878-1902, las inversiones directas habrían de adquirir un nuevo carácter y se transformarían en el principal, si no único, instrumento financiero del país". ${ }^{12}$

Mientras, los británicos reorientaban su viejo interés sobre el área antillana y sus tradicionales inversiones hacia otros ámbitos coloniales de África y Asia, dejando a los estadounidenses en una posición de absoluta exclusividad, haciendo éstos de Cuba un auténtico "mercado reservado de producción y consumo", tan característico de las experiencias colonialistas europeas de fines del XIX.

Proliferaron así grandes compañías de explotación minera con capital norteamericano, como la Juraguá Iron Company de Filadelfia, creada en 1883 y adquirida una año después por la Bethlehem and Pennsylvania Steel Company, dedicada a la extracción de hierro, al igual que la SpanishAmerican Iron Company y la Sigua Iron Company, ambas erigidas en 1892. Dos años más tarde, la Ponupo Manganesse Company activaba notablemente los yacimientos de manganeso en la provincia de Oriente. ${ }^{13}$

Aunque el desarrollo de sus actividades no estuvo exento de avatares, fruto a menudo de las agitaciones políticas, lo cierto es que se alcanzaron niveles destacados de producción, asociados lógicamente a la disponibilidad de capital y a la adopción de un método de explotación sistemático. Debe recordarse que gracias a los capitales británicos llegados a la isla en la primera mitad del siglo, se alcanzaron niveles de desarrollo tecnológico en la minería del cobre muy satisfactorios, con la aplicación del vapor a las tareas de extracción y desagüe de galerías, así como con la contratación de técnicos británicos, manifestaciones de progreso que se vieron interrumpidas con el estallido de la guerra.

En 1884, apenas un año después de su creación, la Juraguá Iron Company exportaba 21.000 toneladas de hierro a Estados Unidos, cifra superada en 1895 por las labores de la Spanish-American Company en los yacimientos de Daiquirí a 74.000 toneladas. ${ }^{14}$ Frente a este panorama, la

12 Le Riverend: Historia económica..., pág. 532.

13 Ibídem, págs. 503 y 532.

14 Ibídem, pág. 503. 
producción de cobre disminuyó extraordinariamente tras la Guerra de los Diez Años, durante la cual se destruyeron las instalaciones de las minas, confiscando el gobierno la propiedad de las mismas. ${ }^{15}$ En cuanto a la extracción aurífera, paralizada asimismo durante la década de contienda, se restableció a partir de 1880, con un sistema de explotación regular y una planta de beneficio en las minas de Holguín, valorándose su producción hasta 1898 en un millón de pesos. ${ }^{16}$

No era, pues, la industria extractiva de Cuba, un ramo de la economía ignorado o prescindible. La vieja metrópoli, conmocionada tanto o más que la propia Cuba por los acontecimientos políticos de aquellas décadas, perdida ya la esperanza de los años 40 de crear una industria minera auténticamente nacional, renovará sus permanentes esfuerzos por ordenar una legislación a veces confusa o contradictoria, y una fiscalidad siempre deficitaria, sin abandonar nunca el interés por descubrir y explotar nuevos yacimientos minerales, ni las medidas proteccionistas sobre el ramo. Estos aspectos se abordarán a continuación.

\section{La problemática minera en Cuba y las iniciativas del gobierno metropolitano}

En primer lugar, consta el deseo de poner fin a las contradicciones derivadas de la normativa del ramo, que ya en la primera mitad del siglo habían generado conflictos jurisdiccionales entre autoridades y favorecido abusos por parte de los empresarios mineros. La confusión provenía de estar vigentes de forma simultánea las Ordenanzas de Minería de Nueva España de 1783 y el Real Decreto e Instrucción provisional de 8 de diciembre de 1825 , haciéndose en cada caso, "una difusa mezcla de ambas disposiciones". ${ }^{17}$

Para poner fin a dicha situación, y considerando "la urgencia que el fomento de la industria minera exige, hoy sensiblemente entorpecido por la deficiencia de la legislación del ramo en aquella Antilla...", el ministro de Ultramar, Gaspar Núñez de Arce, propone en 1883 se declaren vigentes en Cuba la Ley de Minas dictada para la Península el 6 de julio de 1859 y las

15 Ibídem, pág. 210.

16 Ibídem, pag. 208.

17 AHNM, Ultramar, Fomento, 6. Memoria presentada a la Comisión Regia... 1839. 
bases generales para una nueva legislación de minas, aprobadas por Real Decreto de 29 de diciembre de $1868 .{ }^{18}$ Ambas disposiciones tendrían carácter de interinidad hasta la aprobación de una Ley de Minas especial para las provincias de Ultramar que, sin embargo, nunca llegó a emitirse. Con verdadera desesperación la reclamaron incansablemente los sucesivos inspectores de minas de Cuba, tanto Salterain como su sucesor Cantalapiedra. Este último denunciaba en su Estadística Minera de 1894 (!) las contradicciones, el excesivo carácter teórico, lo ficticio y alejado de la realidad de las disposiciones vigentes en Cuba, siendo origen estas circunstancias de innumerables pleitos, "carcoma de esta industria", y puerta abierta a todo tipo de abusos, especulación y codicia. ${ }^{19}$

Un segundo aspecto, y quizá el más importante, porque permitirá valorar en su justa medida el potencial minero de la isla, es el interés permanente del gobierno central por conocer el estado de las explotaciones con vistas a su fomento directo. Esta innegable preocupación está en la base de los nutridos y detallados informes que la Inspección de Minas de Cuba remitió periódicamente al Ministerio de Ultramar, bien que nunca con la exhaustividad que hubiera sido deseable, dada la negligencia de los gobernadores provinciales en la remisión de los estados trimestrales de la producción local, obligación incumplida sistemáticamente.

La reorganización completa de la plantilla de tan notable institución no tendría lugar, sin embargo, hasta 1893, en que se nombró para la demarcación minera de La Habana a don Pedro Salterain y Legarra, ingeniero jefe de $2{ }^{a}$ clase, como jefe de la sección central y occidental de minas, con 3.500 pesos de sueldo, auxiliado por un facultativo de 2 a $^{\mathrm{a}}$ clase $(1.500$ pesos), un escribiente ( 425 pesos) y un ordenanza ( 250 pesos). A la demarcación de Santiago de Cuba fueron destinados don Juan Aguilera Kindelán, como jefe de la región oriental (con 2.500 pesos), y don Vicente Kindelán y de la Torre, adjunto a la misma como 2. ${ }^{\circ}$ jefe del Negociado (con 2.000 pesos), así como un escribiente (300 pesos) y un ordenanza (200 pesos). ${ }^{20}$ A pesar de lo tardío de una medida largamente reclamada por los inspectores de minas, lo cierto es que éstos cumplieron fielmente la labor informativa sobre el ramo que tenían encomendada.

18 Ibídem, 247, 6. Resolución del Consejo de Ministros de 9 de octubre de 1883.

19 Ibídem, 228, 11. Estadística minera de la isla de Cuba para los años 1890, 1891, 1892 y 1893. La Habana, 31 de agosto de 1894.

20 Ibídem, 228, 1. Plantilla del personal de minas de la isla de Cuba. Aprobada por Real Orden dada en Madrid a 13 de agosto de 1893. 
Por Real Orden de 7 de octubre de 1879, se solicita a don Manuel Fernández de Castro, como inspector general de minas en Cuba, la realización de una memoria geológico-minera de la isla, destacándole por especial comisión para ello. Su traslado poco después a la Junta Superior Facultativa de Minas y, posteriormente, a la Dirección de la Comisión del Mapa Geológico de España y como vocal de la Junta Superior de Minería, dejarían esas tareas en manos de otro ingeniero, el mencionado don Pedro Salterain. Este ejercería como jefe de la sección central y occidental de minas en el gobierno general de la isla de Cuba. ${ }^{21}$

De los oficios de ambos al Ministerio se desprende que el gobierno metropolitano quería que se escribiera la historia de la minería de la isla desde su descubrimiento hasta la época actual, tarea que queda pendiente para los historiadores de hoy. Salterain cumplió con exactitud lo que la Real Orden le solicitaba, lo que permite conocer el grado de recuperación de la minería cubana tras la Guerra de los Diez Años, particularmente en las regiones de Santiago de Cuba y Santa Clara. La pacificación del territorio volvió a crear las ventajosas condiciones que el ramo necesitaba para su reconstrucción y desarrollo, siendo numerosos los registros incoados para la extracción de hierro, cobre, oro, manganeso, minerales bituminosos y guano, a cuya explotación se hará referencia en los siguientes apartados.

\section{Minerales de hierro}

Constituyen la más importante fuente de riqueza de la industria extractiva cubana durante la segunda mitad del siglo XIX, privando a la extracción cuprífera del papel protagonista que había acaparado hasta entonces. Se trata de un mineral muy puro y de excelente calidad, extendiéndose sus vetas, de gran potencia y en dirección oeste-este, desde la zona oriental de Santiago de Cuba, hasta aproximadamente 5 ó 6 kilómetros de la costa sur. Los registros de estos criaderos fueron iniciados por el inspector de minas don José Ruiz León, con las minas tituladas "Lola", "Victoria" y "Rosa", constituidas las tres por potentes masas a la vista de hierro oligisto y magnético de gran pureza, "cuyas muestras fueron analizadas en Nueva York y en esta Ynspección...que hoy parece tocan a su término las negociaciones para la organización de una sociedad de considerable capital que ha de emprender los trabajos a grande escala,... pro-

21 Ibídem, 227, 7. 
yectándose... el trazado de un ferrocarril desde la mina "Lola" pasando por las otras dos, a la bahía de Santiago de Cuba". ${ }^{22}$

Se mencionó en el apartado anterior la injerencia en exclusiva del capital norteamericano a través de la creación de compañías para la explotación minera de Cuba durante las décadas finales del siglo XIX. La Sigua Iron Company de Filadelfia adquirió un amplio grupo de minas de hierro invirtiendo un capital de 500.000 dólares sólo en la construcción de un puente y un puerto artificial, así como un ferrocarril desde allí a las minas. El precio pagado por éstas fue de 150.000 dólares efectivo, con un derecho de 30 centavos plata por tonelada en las primeras 60.000 de mena o mineral extraído; 25 centavos plata por tonelada en las siguientes 40.000 y 20 centavos plata por tonelada en todo lo extraído por encima de 100.000 toneladas durante el primer año de trabajo. Conviene recordar que dichas compañías extranjeras solían arrendar las minas a los concesionarios cubanos que las habían denunciado, obteniendo después las demarcaciones del gobierno general de la isla.

Estos datos ilustran tanto la positiva visión del ingeniero de minas en sus informes a la Corona sobre la evolución de la actividad extractiva, como el abandono total del capital británico respecto de su interés por la inversión minera en Cuba. Esta dejación fue dolorosamente denunciada en un informe remitido por el cónsul general inglés en La Habana, A. de C. Crowe, a su gobierno. En sus páginas, fechadas en 1890, Crowe desgrana la fabulosa progresión seguida tras la guerra por la industria del hierro en la isla: el ansia descubridora de yacimientos y la proliferación de denuncias, la existencia en el mercado de varios grupos de minas de brillante promesa y fácil acceso, y la notable pureza del mineral (67\% de hierro puro en algunos casos), así como su creciente nivel de producción, datos refrendados por los dictámenes de los expertos, tanto en la propia Cuba como en los Estados Unidos.

Junto a ello, las exenciones de que disfrutaban dichas explotaciones y otras ventajas, como la facilidad de obtener mano de obra (punto discutible, a juzgar por la visión inversa que sobre este aspecto dan los inspectores de minas) y la creciente demanda de hierro, llevan al cónsul británico a proponer ante el Parlamento tanto el transporte del metal puro a Inglaterra, como la instalación de fundiciones in situ. En suma, pretende la implicación de los inversores británicos en una industria que ofrece todas las ventajas - confirmadas asimismo por los informes consulares alema-

22 Ibídem, 3. 
nes-, pues, insiste, "sería un asunto que remordería a los británicos si por descuido perdieran buenas oportunidades más cerca de casa (tan acostumbrados como están a viajar lejos para hacer dudosas inversiones)". ${ }^{23}$

No es extraño que los cónsules extranjeros en Cuba informasen positivamente del desarrollo de la industria minera del hierro. Desde 1884 a 1893, las estadísticas evidencian una producción creciente e ininterrumpida. Y no debe ignorarse que la extracción de hierro en esos años fue considerablemente superior a la de otros minerales como los bituminosos o el cobre. El siguiente cuadro permitirá apreciar esa evolución: ${ }^{24}$

\begin{tabular}{|c|c|c|c|c|}
\hline Años & \multicolumn{2}{|c|}{ Producción } & Puerto de destino & Exportado en toneladas \\
\hline 1884 & \multicolumn{2}{|c|}{238.770 quintales } & & \\
\hline 1885 & 1.016 .000 & “ & & 79.920 \\
\hline \multirow[t]{2}{*}{1886} & \multicolumn{2}{|c|}{112.755 toneladas } & Filadelfia & 72.205 \\
\hline & & & Baltimore & 40.550 \\
\hline \multirow[t]{2}{*}{1887} & \multirow[t]{2}{*}{92.910} & \multirow[t]{2}{*}{ “ } & Filadelfia & 77.390 \\
\hline & & & Baltimore & 15.520 \\
\hline \multirow[t]{3}{*}{1888} & \multirow[t]{3}{*}{204.425} & \multirow[t]{2}{*}{ “" } & Filadelfia & 144.315 \\
\hline & & & Baltimore & 31.810 \\
\hline & & \multirow{4}{*}{ “ } & Perth Amboy & 28.300 \\
\hline \multirow[t]{3}{*}{1889} & \multirow[t]{3}{*}{304.406} & & & 4.550 \\
\hline & & & Filadelfia & 221.216 \\
\hline & & & Baltimore & 78.640 \\
\hline 1890 & 357.045 & “" & & \\
\hline 1891 & 262.744 & “ & & \\
\hline 1892 & 338.579 & “ & & \\
\hline 1893 & 340.406 & “ & & \\
\hline
\end{tabular}

Los años 90 dieron, como es apreciable, cifras de producción más fluctuantes, afectado el mercado norteamericano por la crisis financiera que obligaría a algunas empresas a presentarse en liquidación, con lo que la explotación de los ricos criaderos de hierro de Santiago de Cuba decayeron en gran medida desde el $2 .^{\circ}$ semestre de 1893 , hasta cuya época iba creciendo.

23 Ibídem, 227. Foreign Office, 1890. Miscellaneous series, n. ${ }^{\circ} 177$. Report on subjects of general and commercial interest. Spain. Further report on the Mineral Deposits of the Island of Cuba. Presented to both Houses of Parliament by Command of Her Majesty. July, 1890. Este informe fue remitido al Ministerio de Estado por el embajador español en Londres, un mes más tarde.

24 AHNM, Ultramar, Cuba, Fomento, 228, 11 (1-3). Estadísticas mineras de la isla de Cuba correspondientes a los años 1884 a 1893 . 
Otro elemento indicador del alto desarrollo de la industria siderúrgica en la isla es el número de operarios empleado para las labores. La Juraguá Iron Company Limited, la más importante compañía norteamericana dedicada desde 1883 en exclusiva a la explotación del hierro, llegó a emplear 1850 obreros en 1892.

El progreso tecnológico y las elevadas inversiones de capital no fueron acompañadas, sin embargo, de ninguna medida sanitaria o protectiva de los empleados, aspecto que ignoró por completo la legislación española sobre el ramo. La Inspección de Minas llamó la atención sobre el hecho de que los índices de accidentalidad y mortalidad en las explotaciones de hierro de Cuba, con frecuentes labores en superficie, eran con mucho superiores a los registrados en las minas de carbón de Francia, cuyas explotaciones resultaban mucho más peligrosas, tanto por su extensión como por las propias características del laboreo, en complejas galerías a mucha profundidad y con constante amenaza de explosiones y desprendimiento de gases tóxicos.

Las principales causas de las desgracias ocurridas en las minas eran, en primer lugar, las explosiones de barreno y, en segundo término, los desprendimientos de rocas y rotura de máquinas, aparatos, cables, etc. Las cifras más elevadas correspondieron siempre a la industria siderúrgica, la que más desarrollo alcanzó en la isla en la segunda mitad del siglo y mayor número de empleados tuvo trabajando en ella. Salterain las calificó en sus informes de "desconsoladoras", pues el número de accidentes y víctimas no hizo sino aumentar a lo largo del período estudiado. Sólo en 1889, de los 1.191 hombres que laboraban las minas de hierro fallecieron 6, sumándose además 197 heridos y 85 contusos, un total, pues, de 288 accidentados.

Estos elevados niveles de accidentalidad se debieron, en gran parte, a la falta de cualificación de los operarios empleados para las tareas de mina. La dificultad para encontrar mano de obra llevó a contratar a gentes sin experiencia, como lo demuestra el hecho de que existieran dos tipos de salario: la Spanish-American Iron Company pagaba 1 peso diario a todos los que no tenían oficio ni arte alguno, y 2 pesos y más a los que lo tenían. La industria minera luchaba con la falta de brazos y, aunque se procuraba fomentar la emigración desde la Península pagando el pasaje a los obreros, no se lograba obtener el número necesario para la actividad desplegada en las minas en la época, lo que permite deducir que los empleados podían estar sobresaturados en las tareas a realizar, lo que también pudo influir en los índices de accidentalidad. 


\section{Minerales de cobre}

Las regiones de Santiago de Cuba y Santa Clara eran, asimismo, los puntos clave de ubicación de los principales yacimientos cupríferos. Es digno de mención el hecho de que las famosas compañías que los explotaron hasta los años 68-70, la Consolidada y la San José, de capital cubano y británico, nunca pudieron recuperarse de los daños causados por la guerra ni reanudar sus trabajos, por lo que las minas tradicionales quedaron abandonadas con posterioridad a esas fechas, y bautizadas significativamente con el nombre de "Ruinas Grandes", pues a sus restos acudían algunos operarios a extraer y beneficiar los residuos que quedaron en superficie. Del antiguo esplendor de aquellos yacimientos, ahora arruinados, da buena muestra lo obtenido en 1887 por la Empresa del Ferrocarril del Cobre sólo con el aprovechamiento de las aguas de lluvia, sin máquina alguna y empleando sólo 8 ó 10 trabajadores, que ascendió a 52 toneladas de cobre cementado con una riqueza del $60 \% .^{25}$

Tras una década de interrupción total de los trabajos de extracción, se detectan en torno a 1880 nuevos registros de minas de cobre en la provincia de Santiago de Cuba, aunque es la de Santa Clara la que parece acaparar el mayor interés. Existen minas de importancia, como la de "San José" de Malezas en la provincia de Santa Clara, cuyos trabajos eran en su mayor parte superficiales, y se detectan registros en las minas "San Fernando" y "Santa Rosa", término municipal de Manicaragua, así como otras cuatro en Cumanayagua.

Sólo la mina de "San Fernando" exportó al puerto británico de Swansea en 17793.253 toneladas inglesas de mineral, por las que se pagaron 54.446 libras 8 chelines, a razón de 7,16 din. la tonelada. Las empresas de fundición de la localidad abonaron a los concesionarios de la "San Fernando" por sus minerales a razón de 16 chelines 82/5 din. por cada unidad de cobre contenida en 100 partes de mineral". ${ }^{26}$ No obstante, la destacada importancia de Gran Bretaña como principal receptor de los productos minerales de Cuba prácticamente hasta los años 60, quedó definitivamente rota en los años 80 y 90, convirtiéndose los Estados Unidos en su mercado natural, como se verá más adelante.

25 Ibídem, 11 (2). Memoria estadística de la isla de Cuba correspondiente al año 1887. Habana, 29 de diciembre de 1888 .

26 Ibídem. 
Los análisis del cobre, realizados por ingenieros norteamericanos comisionados a ese fin por una empresa de Nueva York, llevaron a la constitución, en enero de 1882, de una sociedad por acciones con un capital de 2 millones de pesos para explotar en gran escala las minas "San Fernando" y "Santa Rosa", y todas las que pudieran registrarse en el término de Manicaragua. Ese mismo año, el gobierno general de la isla hizo nuevas concesiones de minas en el mismo término, las tituladas "Caridad", "Mi Fortuna", "La Aventura" y "Portes", laboradas sólo en superficie (el sistema más común en Cuba durante estos años), pero que "muestran un crestón ferruginoso de unos 8 metros de espesor, atravesado de menas de cobre sulfurado, óxido de cobre y carbonatos de cobre...siendo de esperar que entre las muchas vetas descubiertas...y las que hoy son objeto de otros registros en tramitación, llegue a constituirse un centro de explotación tan rico e importante como el de las minas antiguas del cobre, que coadyuvarán en gran manera a la inmediata reconstrucción industrial de la provincia.....". ${ }^{27}$

En resumen, la minería extractiva del cobre pugna, en la década del 80 , por salir a flote tras la desolación provocada por la guerra, y cuenta para ello con el interés de algunos concesionarios particulares, que emprenderán prospecciones a la búsqueda de nuevas vetas, pero nunca recuperaría el esplendor de que disfrutó en la primera mitad del siglo, sumiéndose, de hecho, en una progresiva decadencia hasta el fin del período colonial. Las cifras de producción son bien expresivas al respecto: ${ }^{28}$

\begin{tabular}{|c|c|c|c|c|c|c|}
\hline Años & ovincia y puert & o embar & Puerto destino & Pro & ducción & Exportado (toneladas) \\
\hline 1884 & Santiago de & Cuba & Nueva York & 673,18 & quintales & 34,42 \\
\hline & “ & “ & Bremen & & & 6 \\
\hline 1885 & “ & " & & 211,90 & “ & 58,62 \\
\hline 1886 & “ & “ & Liverpool & 45,06 & toneladas & 45 \\
\hline 1887 & “ & “ & Filadelfia & 57 & “ & 24 \\
\hline & “ & “ & Liverpool & & & 28 \\
\hline 1888 & “ & “ & Liverpool & & & 21,680 \\
\hline 1889 & “ & “ & Filadelfia & 35,700 & toneladas & 23,330 \\
\hline & “ & “ & Baltimore & & & 12,370 \\
\hline 1890 & “ & “ & & 12,084 & “ & \\
\hline 1891 & “ & “ & & 18,400 & “ & \\
\hline 1892 & “ & “ & & 25,33 & “ & \\
\hline 1893 & “ & “ & & 10,5 & “ & \\
\hline
\end{tabular}

27 Salterain, Pedro: Breve reseña de la minería de la isla de Cuba. La Habana, 1883, págs. 11 y 12 .

28 AHNM, Ultramar, Cuba, Fomento, 228, 11 (1-3). Estadísticas mineras... 


\section{Minerales de oro}

La zona aurífera se encontraba situada en la provincia de Santa Clara, en el término municipal de Guaracabuyá. La situación al término de la Guerra de los Diez Años es análoga a la mencionada para otras explotaciones minerales (paralización de labores, nuevos registros en los años 80, escaso número de concesiones en explotación, etc.), aunque es sabido que la extracción de oro siempre ocupó en Cuba un lugar secundario. Y es así hasta el punto de que las estadísticas de producción minera no recogen siquiera las cifras correspondientes al oro.

El foco de atención se dirige en 1882 hacia los criaderos de oro del distrito de Holguín, en la provincia de Santiago de Cuba, los cuales, tras los ensayos realizados en 1855 por el ingeniero don Diego López de Quintana, parecían ofrecer grandes posibilidades. Sin embargo, las minas nunca fueron objeto de trabajos sistemáticos de exploración de las vetas, y las concesiones realizadas, tanto a sociedades como a particulares, fueron constantemente abandonadas, hasta el punto de que en 1882 sólo se encuentra en explotación la mina denominada "La Central", perteneciente a don Vicente Guillén. Dicha mina, aunque cuenta con pozos, entibado, oficinas de beneficio e instrumentos para pulverización en molino, amalgama con mercurio y destilación, son éstos "aparatos bastante imperfectos, costando cara la mano de obra y obrando lentamente, siendo por lo tanto inadmisible para la explotación en grande escala". ${ }^{29}$

Estos hechos vienen a poner de manifiesto "El poco espíritu industrial del país, debido... a la riqueza agrícola que ha absorbido todos los capitales, desatendiendo la minera que exige conocimientos especiales, operarios expertos en esta clase de trabajos y que se halla expuesta a mayores eventualidades en su producción". ${ }^{30}$

\section{Minerales bituminosos}

Se presentan en Cuba bajo tres estados, sólido, pastoso o líquido, dependiendo de la roca del terreno, que es determinante, asimismo, de su pureza. El pastoso y el líquido no fueron objeto de una verdadera explotación, aunque en algunas fincas se aprovechaban como combustible y para

29 Ibídem, 227, 3. Memoria minera..., fol. 41.

30 Ibídem. 
el alumbrado. Lo significativo es que su presencia constituía un indicio más que fiable de la existencia en profundidad de aceites bituminosos más ligeros o del aceite del petróleo, "que en otras condiciones de desarrollo de la industria, habrían motivado trabajos de investigación más formales y numerosos que los muy escasos de sondeo llevados a cabo hasta ahora". De gran importancia fue el asfalto de la bahía de Cárdenas, con un espesor de más de 70 pies, extendido como un manto sobre el suelo de la misma, constituyendo "un mineral bituminoso de los más puros que se conocen y muy apreciado en el mercado de Nueva York para su empleo en los barnices, donde alcanza un valor de 80 a 110 pesos por tonelada". ${ }^{31}$

Otras minas de asfalto sólido se explotaron en la isla: "Cayo Diana" y "Cayo Cupey", "Santa Rosa" en el término de Guanabacoa, provincia de La Habana; "Magdalena", "Concepción" y "Rodas" en el término de Mariel; y "San José" y "Constancia" en Banes, provincia de Pinar del Río. La producción de asfalto desde julio de 1880 a diciembre de 1881 ascendió a 2.224 toneladas, con un valor de 193.816 pesos en el mercado de Nueva York. ${ }^{32}$ Sin embargo, la producción total del período no resultó muy elevada debido, fundamentalmente, a la escasa demanda del mercado estadounidense, que se surtía del mismo en la isla de Trinidad.

Con gran entusiasmo se informó al gobierno central en 1881 del descubrimiento, a 95 metros de profundidad, de un depósito de aceite mineral de pureza extraordinaria, sin residuos, fácilmente inflamable, de densidad 0,754; en suma, un aceite de nafta puro. El concesionario del yacimiento, don Manuel de Cueto, que había fracasado anteriormente en la perforación de la mina "San Juan", en la hacienda Motembo de la provincia de Matanzas, lograría esta vez pasar en sólo un año, de una producción de 25 galones diarios a 250, al llegar a perforar hasta una profundidad de 816 pies (248,72 metros).

La importancia del asfalto en Cuba radicaba tanto en su abundancia como en la variedad de aplicaciones, entre ellas como combustible en la fabricación de gas de alumbrado. Muchos ingenios lo incorporaron para sus hornos, pero fue la Compañía Española de Gas de La Habana la que obtuvo, en su ingeniero José Paz Peraza, el privilegio del gobierno general para la fabricación de panes o ladrillos de asfalto con mezcla de otras sustancias, que ardían perfectamente en los hornos sin derretirse ni perder su forma, y con una potencia calorífica igual a la del carbón de piedra. Los

31 Ibídem, fol. 47.

32 Ibídem, fol. 47. 
ensayos se realizaron en el ferrocarril de Villanueva, dando excelentes resultados en las locomotoras.

Las estadísticas emitidas por la Inspección de Minas al Ministerio de Ultramar resultan significativas del desarrollo de la industria: ${ }^{33}$

\begin{tabular}{|c|c|c|c|c|}
\hline Años & Provincia y puerto embarque & Puerto destino & Producción (toneladas) & (Exportadas) \\
\hline 1884 & Habana, Pinar del Río, Matanzas & Nueva York & 6.049 & 6.049 \\
\hline 1885 & “ & & 466,74 & \\
\hline 1886 & La Habana & Panzacola & 1.403 & 140 \\
\hline “ & “ “ " & Nueva York & & 484 \\
\hline “ & “ & Bremen & & 101 \\
\hline “ & “ “ “ & & & 345 \\
\hline “ & Cárdenas & Liverpool & & 19 \\
\hline “ & “ & Delaware & & 102 \\
\hline “ & “ & Nueva York & & 137 \\
\hline “ & Caibarien & Bremen & & 75 \\
\hline 1887 & La Habana & Mobila & 870 & 380 \\
\hline “ & " " $"$ & Nueva York & & 8 \\
\hline “ & Cárdenas & “ “ “ & & 422 \\
\hline “ & “ & Liverpool & & 28 \\
\hline “ & “ & Londres & & 8 \\
\hline “ & Caibarien & Nueva York & & 24 \\
\hline 1888 & Cárdenas & Nueva York & 575 & 135 \\
\hline “ & “ & Galveston & & 105 \\
\hline & La Habana & Nueva York & & 252 \\
\hline “ & " " " & Liverpool & & 31 \\
\hline “ & " $\quad ،$ & Bremen & & 50 \\
\hline 1889 & Cárdenas & Nueva York & 765 & 242 \\
\hline “ & La Habana & Hamburgo & & 521 \\
\hline 1890 & & & 1.038 & \\
\hline 1891 & & & 274 & \\
\hline 1892 & & & 375 & \\
\hline 1893 & & & 0 & \\
\hline
\end{tabular}

\section{Minas de manganeso}

Existían minerales de manganeso en muchos puntos de la provincia de Santiago de Cuba, pero en 1883 no habían sido objeto de explotación, fundamentalmente por su escaso valor en el mercado norteamericano $(0,36$ pesos oro por unidad, siempre que su riqueza no bajase del $45 \%)$, a pesar de su excelente calidad y relativa riqueza.

33 Ibídem, 228. Estadísticas mineras... 
Ese mismo año la Inspección de Minas registró sólo dos en el ingenio de Santa Margarita del Quemado, término de Alto Songo, propiedad de don Francisco Portuondo. La mina "Isabelita", de la que se le concedió título de propiedad, presentaba peróxido de magnesio formando vetas y bolsadas de cierta consideración en el jaspe rojo. ${ }^{34}$

La extracción de magnesio presenta cifras modestas y fluctuantes en los informes estadísticos de dicha oficina; en 1886, con 2 operarios trabajando, se obtuvo una producción de 39,59 toneladas, exportadas 4 a Nueva York y 35 a Filadelfia; en 1887, con 3 operarios y destino Nueva York, sólo 5 toneladas. En 1888, y gracias al impulso y capital de la Cuba Manganesse Company, se contrataron un número considerable de minas de Santiago de Cuba para su explotación, con lo que la producción ascendió a 1.923 toneladas procedentes de las minas "Isabelita", "Boston" y "Ponupo", exportadas a Filadelfia (1.313 toneladas), Baltimore (599 toneladas) y Nueva York (10 toneladas). Sin embargo, la falta de fondos obligó a la compañía a dejar de satisfacer el importe del arrendamiento a los concesionarios, debiendo traspasar sus derechos a otra compañía, que tuvo la misma suerte, "por lo que las ricas minas de manganeso se encuentran en la actualidad sin explotación alguna, pues de tal no debe considerarse los pequeños trabajos que algunos propietarios hacen por cuenta propia en sus concesiones". ${ }^{35}$

En 1889 la producción había descendido a 699 toneladas, exportadas a Filadelfia (392 toneladas), Baltimore (298 toneladas) y Nueva York (sólo 8 toneladas). A pesar de este sombrío panorama, la producción de manganeso terminó recuperándose en los años 90, gracias a la poderosa Ponupo Manganesse Company, que reactivó los yacimientos de la región de Oriente, obteniendo cifras notables de producción: 1890, 19.764 toneladas con 301 operarios en las minas; 1891, 14.529 toneladas, con 318 trabajadores; $1892,14.925$ toneladas, con 185 hombres y 1893, 13.349 toneladas, con 137 operarios. $^{36}$

\section{Guano}

Los cayos de la costa sur de Cuba y las numerosas y grandiosas cuevas de las sierras de la provincia de Santa Clara y Pinar del Río fueron los lugares de depósito de excrementos de aves como murciélagos y guanays

34 Salterain, Pedro: Breve reseña de la minería..., pág. 17.

35 AHNM, Ultramar, Cuba, Fomento, 228, 11 (1-3). Estadísticas mineras...

36 Ibídem. 
entre otras, cuya composición química (sales amoniacales, fosfatos de cal, ácido fosfórico, amonio, potasio, sodio, etc.), hacía de él en el siglo pasado un excelente abono agrícola — su uso fundamental desde 1840 en que comenzó su explotación-, y un remedio para algunas enfermedades oculares y dérmicas.

Debe reseñarse lo científico y sistemático de la explotación del guano en Cuba, iniciada en 1879 con la adjudicación para ello, en pública subasta, a don Lorenzo Ferrán, y respaldada por los análisis de su composición por 60 químicos norteamericanos (entre ellos el ilustre J. Y. Lehmann, de Baltimore), quienes dieron fe de su excelente calidad. ${ }^{37}$

La más destacada explotación estuvo situada en Cayo Abalos, donde, tras largos y muy costosos reconocimientos en 1881, se detectó una capa de guano en superficie con una extensión de 1 milla de largo por 0,5 de ancho y unos 3 pies de espesor. La extracción de mineral en sólo año y medio (mediados de 1880 a finales de 1881), pasó de emplear 53 operarios, a requerir la contratación de 104.

Sobre el cayo se erigieron casas y almacenes de gran tamaño importados de Estados Unidos. Para el transporte y embarque del guano se utilizaba un ferrocarril portátil de una milla de largo, cuatro mulos y un muelle de 41 metros que alcanzaba un fondo de 1 1/2 metros para hacer el "lanchage", que se efectuaba por medio de seis carros de volteo y seis lanchas de 4 a 4 1/2 toneladas. Con objeto de facilitar la arribada de los buques, se colocaron boyas en una extensión de 11 por 5 millas. Y para el servicio necesario entre la isla y el cayo, contaban con una goleta de 53 toneladas y otra de 27 , las que además servían tanto para el reconocimiento de otros cayos como para la investigación de nuevos depósitos de guano. El número de toneladas exportadas desde julio de 1880 a fin de diciembre de 1881 , ascendió a 2.413,99, que devengaron al Estado 9.655 pesos. El mercado para esta producción fueron los Estados Unidos, destinándola a sus plantaciones sureñas de algodón.

A lo producido por esta industria se agregaban los ingresos obtenidos por derechos de tonelaje de arqueo de los buques que exportaban el mineral, así como los satisfechos por los de importación de casas, herramientas, abanderamiento de goletas, etc. Conviene reseñar que el guano fue el úni-

37 Ibídem, 227. 9. Decreto del gobierno general de la isla de Cuba de 27 de mayo de 1879 adjudicando a don Lorenzo Ferrán la explotación del guano por 10 años. Ibídem. Memoria minera..., fol. 61. Resultado del análisis de guano en pedazos recibido en 9 de agosto de 1881 de P. de Murguiondo. Baltimore, 23 de agosto de 1881 . 
co producto mineral de Cuba no eximido del pago de derechos a la Real Hacienda, frente al exacerbado proteccionismo que ejerció el Estado sobre los demás productos de la industria extractiva.

Este hecho llevaría al inspector de minas Pedro Salterain, a recomendar en sus informes la conveniencia de que la Corona protegiese una industria tan incipiente, amenazada por la competencia del guano de los cayos de otras Antillas extranjeras (del que se surtían los Estados Unidos), y sujeta a grandes inversiones por parte del concesionario, que obtenía, sin embargo, el bajo precio de 20 pesos por tonelada. El estudio de esta proposición fue lento y minucioso, con elaborados informes del gobernador general de Cuba, de la Junta Superior Facultativa de Minería y del Ministerio de Ultramar, hasta que el Consejo de Estado en pleno, basándose en que el guano era una sustancia mineralizada peculiar, tanto por lo especial de los afloramientos en que se presenta, como por acumularse generalmente en tierras de propiedad particular, así como por su aplicación agrícola, dictaminó en 1895, su no equiparación en exenciones impositivas al resto de minerales de la isla, ${ }^{38}$ a pesar de lo cual no vuelve a haber dato alguno desde 1881 en los memoriales estadísticos de los inspectores de minas, ni sobre producción, ni sobre derechos devengados al Estado.

\section{Conclusiones}

La isla de Cuba constituyó un ámbito territorial de gran riqueza geológica, tanto por la variedad de sus minerales como por la pureza y alta ley de los mismos, conocidas mediante informes de la Inspección de Minas y por procedimientos de ensayo realizados por expertos de la propia oficina y de las empresas norteamericanas que tenían intereses en la zona.

$\mathrm{Su}$ explotación en la segunda mitad del XIX fue prioritaria para el gobierno metropolitano, que dictó numerosas disposiciones para fomentar la industria extractiva, teñidas todas ellas de un proteccionismo a ultranza que, lejos de favorecer su desarrollo, abrió paso a la especulación y al fraude. Las franquicias otorgadas en la dotación de insumos se combinaron con el abandono en las leyes mineras de las más elementales exigencias para los denunciantes y concesionarios de yacimientos, que no dudaron en acaparar terrenos para arrendarlos ulteriormente a las compañías extranjeras.

38 Ibídem, 22. Consulta del gobernador general de Cuba sobre si el guano de murciélago se halla o no comprendido entre las sustancias que son objeto de la Legislación de Minas vigente en Cuba. Resolución del Consejo de Estado de 22 de julio de 1895. 
Un aspecto del máximo interés para la comprensión de la evolución seguida por la minería cubana, es el de las exenciones otorgadas por el gobierno peninsular. No son una novedad de la segunda mitad del siglo XIX; existieron desde los mismos inicios de la actividad extractiva, concebidas como gracia temporal y extraordinaria y concedidas a determinados empresarios para favorecer las explotaciones. Consistían en la exención de derechos como la alcabala en la compra de esclavos como mano de obra para las minas, así como para la adquisición de combustible, herramientas, maquinaria, vigas de madera o cualquier otro de los insumos exigidos para el laboreo.

La liberalidad con que estas medidas se interpretaron y aplicaron en Cuba, constituyeron un grave perjuicio a los intereses de la Corona ya en la primera mitad del XIX,${ }^{39} \mathrm{y}$ alcanzan su máxima cota en los años que ahora nos ocupan.

La Ley de Franquicias mineras de 1883, concedía la exención total de derechos arancelarios por 20 años en la importación de efectos destinados a la industria metalúrgica, ampliada después a las de asfalto y petróleo y más tarde a todos los minerales a excepción del guano ${ }^{40}$ Curiosamente, las compañías ferrocarrileras no gozaron de estas ventajas, a pesar de resultar fundamentales para la mejora de la deficitaria red de comunicaciones de la isla.

Esta actitud proteccionista del Estado español sobre la industria extractiva de sus últimos territorios coloniales implicó, lógicamente, la pérdida de cuantiosos ingresos por ese concepto, valorados por la Inspección de Minas de Cuba en 109.483 pesos sólo en el lustro 1884-1889. ${ }^{41}$ Sin embargo, y según el criterio de los máximos profesionales del ramo en Cuba, fueron los defectos de una legislación absolutamente permisiva lo que llevaría a la paralización de las notables expectativas de la minería isleña.

La excesiva facilidad para obtener concesiones de minas, junto a la supresión de la obligación que antes exigían las leyes de trabajar los yacimientos, unida a la exención total del canon de superficie y del impuesto sobre la producción, derivó en todo tipo de abusos. Los más frecuentes consistían en denunciar minas donde a veces no existían minerales que explotar, o de minerales distintos a los solicitados, algo explicable si se recuerda que dejó de ser obligatorio el reconocimiento de los criaderos, como lo era en el pasado.

39 Fernández Alonso, S. y Moyano Bazzani E. L.: "Problemas de reforma...".

40 AHNM, Ultramar, Cuba, Fomento, 227, 12. Gaceta de Madrid, 3 de julio de 1887.

41 Ibídem, 228, 11 (1-3). Estadísticas mineras... 
Estos hechos implican que el número de minas denunciadas y concedidas, en ascenso durante todo el período, no sea indicativo de las que se encontraban en explotación, pues sólo una parte mínima de ellas se laboreaba. La propia Juraguá Iron Company, la empresa más activa e importante de los años 80 y 90 (con más de 1.000 empleados en las labores de mina), era propietaria de 17 concesiones en Santiago de Cuba, de las que sólo trabajaba 7 en 1888 y 1889.

Escandalizado reclama en 1894 el ingeniero Cantalapiedra una solución a estos abusos: “...en nuestro país se da, por excepción, el singular y raro caso, desde la última llamada Ley de Minas, (...) de que el Estado da una cosa cuya existencia no le consta, haciendo, como suele decirse, la vista gorda....". ${ }^{42}$

Los intentos de reforma en este sentido por parte del gobierno central no tuvieron efecto alguno. La Instrucción de 7 de julio de 1892 respetaba las franquicias para todas las minas puestas en explotación con anterioridad al 1 de julio de 1890, pero pretendía volver a cobrar el canon de superficie y el $2 \%$ sobre el producto a las minas en activo a partir de entonces. Muestra del escaso éxito en la aplicación de la medida fue que en 1895 se recaudaron 278 pesos en 11 meses por esos conceptos, frente a los 15.000 que el Estado esperaba recaudar según sus presupuestos. ${ }^{43}$ Faltaron registros adecuados y hubo confusión, deliberada o no, en la interpretación de las medidas por parte de las administraciones locales. En cualquier caso, no era posible borrar de un plumazo la tónica general de los últimos 20 años de privilegios y exenciones.

En la misma línea, en 1890 la Junta de Obras del puerto de Santiago de Cuba, promovió un expediente para que se le autorizase a cobrar a las empresas mineras un arbitrio sobre los artefactos que introducían por dicho puerto, con el fin de atender a las obras emprendidas, basándose en que dichas empresas serían las primeras en beneficiarse de las mismas, pues las tareas de carga y descarga de mercancías no habrían de verse interrumpidas con la llegada de la noche.

“...las empresas mineras establecidas en esta capital y cuyo desarrollo es bien notorio, constantemente tienen los muelles ocupados con los artefactos a ellas destinados, dándose el caso con frecuencia de ser imposible utilizarlos con las mercancías de trá-

42 Ibídem, 11 (3). Habana, 31 de agosto de 1894.

43 Ibídem, Ultramar, Hacienda, 965. Informe de la Mesa de Subsidio del Negociado Central de Contribuciones. Habana, 28 de febrero de 1895. 
fico ordinario y natural del comercio... esta Corporación ve que el desarrollo de esta industria toma proporciones gigantescas, compite con las del extranjero en riqueza y facilidades para su extracción del mineral, se nota su crecimiento por el movimiento de los buques que frecuentan el puerto....".4

A pesar de esta exaltadora visión sobre el progreso de la industria minera y de lo modesto de la tasa que se propone (10 centavos de peso por cada 100 kilos de material y maquinaria importados), el Consejo de Administración de la isla de Cuba, y finalmente el Consejo de Estado, lo desestiman en sus dictámenes, apoyados en la Ley de Franquicias mineras ya mencionada.

La Real Hacienda no sólo perdió así definitivamente su posibilidad de recabar ingresos procedentes de dicha actividad, sino que dejó la industria en manos del capital norteamericano, que dirigió las operaciones extractivas a través de sus compañías y se convirtió en el mercado principal de los minerales extraídos, fundamentalmente hierro y asfalto y, en menor cuantía, manganeso, guano y cobre. Mientras, Gran Bretaña reorientaba sus intereses financieros hacia otros ámbitos coloniales, siendo receptor de productos minerales cubanos a gran distancia de los Estados Unidos, perdiendo el papel protagonista que había disfrutado en la primera mitad del siglo.

Los tímidos intentos de reforma del gobierno central en orden a reordenar la actividad minera y recuperar el control fiscal sobre la misma, chocarían con la desinformación y el inmovilismo locales. Dicho impulso, muy poco vigoroso por cierto, no es manifiesto hasta 1892 , fecha demasiado cercana a los tristes acontecimientos que abrirían paso a una nueva contienda, tras la cual España perdería sus últimos reductos de dominio colonial en América.

44 Ibídem, Ultramar. Fomento, 228, 12, n. ${ }^{\circ}$ 601. Propuesta de la Junta de Obras Públicas del puerto de Santiago de Cuba. 18 de diciembre de 1890. Resolución del Consejo de Estado de 23 de abril de 1891. 